\title{
FAKTOR PENDUKUNG EKSTERNAL DAN PENGADOPSIAN E-COMMERCE PADA UKM: SEBUAH MODEL KONSEPTUAL
}

\author{
Hendrick Hernando \\ Alumni Magister Manajemen Universitas Diponegoro \\ Perum. Permata Residence C-6, Jombang (61416) \\ Hp. 082254848307 \\ hernando.hendrick@gmail.com
}

\begin{abstract}
Abstrak: Perkembangan teknologi informasi dan perdagangan berbasis elektronik memberi peluang bagi para pelaku usaha kecil menengah di Indonesia untuk mengembangkan bisnisnya. Hal tersebut sejalan dengan visi pemerintah yang menargetkan Indonesia untuk menjadi negara ekonomi digital terbesar di Asia Tenggara pada 2020. Namun, pengadopsian teknologi untuk perdagangan berbasis elektronik memiliki kendala, salah satunya mengenai kesiapan sumber daya manusia. Para pelaku usaha kecil menengah lebih fokus untuk menilai aspek finansial dibandingkan dengan kapabilitas internal ketika berhadapan dengan implementasi teknologi informasi. Studi ini bertujuan untuk membangun sebuah model konseptual yang menjelaskan hubungan antara faktor pendukung eksternal, penguasaan IT dan pengadopsian e-commerce pada UKM. Studi ini diharapkan dapat memberi implikasi kepada pelaku usaha, pemerintah sebagai pembuat kebijakan dan perusahaan pengembang teknologi untuk dapat berkolaborasi bersama dalam pencapaian visi ekonomi digital.
\end{abstract}

Kata kunci: UKM, pengadopsian e-commerce, faktor pendukung eksternal, penguasaan IT

\begin{abstract}
Development in information technology and electronic-based trading provides opportunities for small and medium enterprises in Indonesia to develop their business. This is in line with the government's vision targeting Indonesia to become the largest digital economic country in Southeast Asia in 2020. However, the adoption of technology for electronic-based trading has barriers, one of them is the readiness of human resources. The small and medium enterprises are more focused on assessing the financial aspects compared to the internal capabilities when dealing with the implementation of information technology. This study aims to develop a conceptual model that describes the relationship between the external support factors, IT ability and the adoption of e-commerce on SMEs. This study is expected to have implications to SMEs, government as policy maker and developer companies of technology in order to collaborate together in achieving the vision of digital economy.
\end{abstract}

Keywords: SMEs, e-commerce adoption, external support factors, IT ability

\section{Latar Belakang}

\section{PENDAHULUAN}

Usaha kecil menengah (UKM) memiliki beberapa keterbatasan, salah satunya cakupan pasar yang relatif sempit. Produk pada UKM kurang dikenali dan hanya digunakan oleh segelintir orang, di mana sudah sejak lama mereka terlibat kerja sama transaksional. MacGregor dan Kartiwi (2010) menyatakan bahwa UKM cenderung menggantungkan permintaan produknya pada sejumlah kecil pelanggan. Namun, pada era persaingan bisnis saat ini UKM berpeluang untuk dapat mengakomodir pasar yang lebih luas jika mampu beradaptasi dengan perkembangan teknologi (Sin et al., 2016). Ketika produk dikenal oleh lebih banyak orang maka peluang terjadinya transaksi akan jauh lebih besar. Perdagangan dengan sistem online memungkinkan penyederhanaan aktivitas transaksi, pelanggan dapat melakukan pemesanan tanpa terkendala oleh faktor tempat dan waktu (Kotler, 2009 dalam Suryana et al., 2013). Keuntungan berupa penghematan biaya transaksi menjadi hal utama yang dirasakan oleh UKM di negara berkembang dari penerapan sistem e-commerce (Molla dan Heeks, 2007). Mereka dapat menghemat biaya merchandising yang secara konvensional membutuhkan tempat atau bantuan pihak lain, seperti ritel dan distributor untuk penjualan produk.

Peran UKM yang terbukti vital di berbagai belahan dunia menarik minat peneliti untuk mengkaji pengadopsian e-commerce. MacGregor dan Kartiwi (2010) 
dalam publikasinya melakukan perbandingan kendala dari pengadopsian e-commerce pada UKM di negara maju dan berkembang. Berbicara mengenai kategorisasi negara bukan hanya didasarkan pada aspek ekonomi semata, tetapi juga faktor sosial budaya (Gattiker et al., 2000; Palvia dan Vemuri, 2002 dalam MacGregor dan Kartiwi, 2010). Pengadopsian e-commerce pada UKM di negara berkembang menjadi menarik bagi para peneliti karena adanya perbedaan karakteristik sosial budaya (Rahayu dan Day, 2015). Hal tersebut menyebabkan hasil penelitian di negara maju tidak dapat digeneralisasi untuk kasus di negara berkembang. Beberapa penelitian telah dilakukan untuk mengkaji determinan pengadopsian e-commerce pada UKM di negara berkembang (Ahmad et al., 2014; Kurnia et al., 2015; Rahayu dan Day, 2015; Sin et al., 2016). Namun, dari hasil penelitian tersebut masih ditemukan adanya inkonsistensi yang belum mampu dijelaskan.

Salah satu penentu suksesnya pengadopsian e-commerce adalah keterlibatan pemerintah dengan perusahaan pengembang sistem/teknologi. UKM dengan segala bentuk keterbatasannya membutuhkan dukungan, baik dari pemerintah maupun perusahaan pengembang. Pemerintah dapat melakukan suatu intervensi melalui kebijakan dan regulasi untuk menstimulus penggunaan internet pada transaksi jual beli (Kuan dan Chau, 2001 dalam Ahmad et al., 2014). Interaksi ketiga entitas yakni pemerintah, perusahaan pengembang dan UKM pada konteks ini dapat dimaknai sebagai interaksi mutualisme. UKM yang secara kuantitas begitu besar menjadi sasaran bisnis bagi perusahaan pengembang. Sementara, pemerintah akan mendapatkan manfaat dari peningkatan nilai transaksi digital yang cukup kontributif untuk perekonomian.

\section{Fenomena Bisnis}

Pemerintah Indonesia melalui Kementrian Perdagangan dan beberapa stakeholders berkomitmen untuk memfasilitasi UKM pada ruang bisnis digital atau e-commerce. Transaksi e-commerce di Indonesia tahun 2015 mencapai Rp. 150 triliun atau sekitar USD 11 miliar (kemendag.go.id, 2016). Nilai tersebut berpotensi untuk terus meningkat jika melihat pertumbuhan pengguna internet. Menurut riset e-marketer jumlah pengguna internet di Indonesia pada 2017 diproyeksikan akan mencapai 112.6 juta, meningkat 34.5\% dari tahun 2014 yang berjumlah 83.7 juta (kominfo.go.id, 2014). Oleh sebab itu, pemerintah mernagetkan pada tahun 2020 Indonesia menjadi negara ekonomi digital terbesar di Asia Tenggara. UKM diharapkan dapat berkolaborasi dan terlibat aktif dalam ekosistem bisnis e-commerce. Namun, menurut Enny V. Panggabean (Direktur Eksekutif Departemen Kebijakan Sistem Pembayaran BI), penggunaan kanal digital untuk pemasaran produk pada UKM masih rendah (kompas.com, 2016). Hanya 9\% UKM yang memiliki tingkat pengetahuan teknologi digital mumpuni. Rendahnya pengetahuan dan kemampuan sumber daya manusia menjadi kendala dari pengadopsian e-commerce pada UKM. Menurut M. Rosidi (Deputy Director ICT Strategy Huawei Indonesia), sisi kemampuan teknis seringkali diabaikan oleh para pelaku UKM saat berhadapan dengan investasi teknologi informasi (metrotvnews. com, 2017). Investasi yang utama bukan terletak pada pengadaan infrastruktur atau proyeksi keuntungan, namun lebih kepada kesiapan sumber daya manusia untuk masuk dalam industri bisnis digital.

\section{Rumusan Masalah}

Deviasi harapan yang diketahui dari pemaparan fenomena bisnis memperlihatkan bahwa tingkat pemanfaatan teknologi informasi dan internet pada UKM di Indonesia masih tergolong rendah. Faktor kompetensi SDM ditengarai menjadi akar dari permasalahan tersebut. Mengingat interaksi antara pelaku usaha kecil menengah, pemerintah dan perusahaan pengembang diyakini dapat saling menguntungkan, maka rumusan masalah penelitian dalam studi ini "Bagaimana meningkatkan pengadopsian e-commerce pada usaha kecil dan menengah dengan mempertimbangkan faktor pendukung eksternal dan penguasaan teknologi informasi ?".

\section{TELAAH PUSTAKA}

\section{Konsep E-Commerce}

Implementasi teknologi digital dipandang sebagai bagian yang tidak terpisahkan dalam strategi bisnis. Keberadaan fasilitas internet dengan sistem penunjangnya dapat membantu 
perusahaan untuk menciptakan nilai pada barang atau jasa yang ditawarkan. Jauh sebelum menjamurnya fasilitas internet, penggunaan teknologi digital dalam konteks bisnis dimaksudkan untuk alasan efisiensi. Ahmad et al. (2014) menyatakan bahwa pengelolaan informasi internal perusahaan yang didukung oleh teknologi digital dapat meningkatkan efisiensi dari proses bisnis. Seiring terbukanya akses internet pada masyarakat umum, penggunaan teknologi digital dalam bisnis mencakup aktivitas pemasaran bahkan transaksi jual beli. Aktivitas jual beli dengan memanfaatkan fasilitas internet lebih familiar dengan istilah e-commerce. Laudon dan Traver (2003) dalam Ahmad et al. (2014) menawarkan definisi e-commerce dalam bentuk teknologi yang digunakan untuk mendukung transaksi bisnis online antara organisasi bisnis (B2B) atau langsung dengan konsumen akhir (B2C). Berbeda dengan Laudon dan Traver, Turban et al. (2010) dalam Ahmad et al. (2014) mendefinisikan e-commerce sebagai sekumpulan proses transaksi produk, jasa dan pertukaran informasi menggunakan jaringan komputer intranet maupun internet.

Implementasi e-commerce saat ini tidak hanya dilakukan oleh organisasi bisnis berskala besar. Terdapat kecenderungan pertumbuhan yang signifikan dari implementasi e-commerce pada usaha kecil dan menengah (UKM) di berbagai belahan dunia (Poon dan Swatman, 1999; Mirchandani dan Motwani, 2001 dalam Molla et al., 2006). Berbeda dengan implementasi pada perusahaan besar, e-commerce pada UKM jauh lebih sederhana. Implementasi pada kebanyakan UKM masih masuk dalam kategori entry level seperti penggunaan browser dan websites (Cloete et al., 2002). Hal tersebut menyebabkan UKM tidak mampu memaksimalkan manfaat dari keberadaan e-commerce. Sesungguhnya keuntungan jual beli dengan sistem digital bagi UKM tidak terbatas pada efisiensi dan fleksibilitas operasional, namun juga meliputi aspek pemasaran. Produk yang sebelumnya hanya dikenal dalam lingkup pasar lokal, saat ini berpeluang untuk merambah ke pasar yang lebih luas. Namun, pengembangan sistem e-commerce bisa menjadi sangat mahal bagi UKM (Suryana et al., 2013). Pada akhirnya implementasi e-commerce untuk UKM akan sangat bergantung pada ketersediaan dana dan tingkat kompetensi.

\section{Determinan Pengadopsian E-Commerce}

Penelitian mengenai determinan pengadopsian e-commerce pada UKM mengacu padabeberapa macam teori. Salah satu teori yang cukup familiar ialah technological, organizational and environmental framework (TOE). Teori ini pertama kali dikembangkan oleh Tornatzky, Fleischer dan Chakrabarti pada tahun 1990 dalam rangka menjelaskan pengaruh faktor kontekstual terhadap adopsi inovasi (Rahayu dan Day, 2015). Teori TOE menjadi pilihan oleh para peneliti dan cukup well-established karena melibatkan beragam aspek dalam mengkaji pengadopsian e-commerce, tidak seperti teori lain yang hanya fokus pada aspek teknologi (Rahayu dan Day, 2015). Secara sederhana, teori TOE mendeskripsikan faktor-faktor yang menentukan kesuksesan pengadopsian teknologi. Faktor teknologi, dalam hal ini melihat seberapa besar manfaat yang mungkin dapat diperoleh organisasi ketika teknologi tersebut digunakan. Selain itu, faktor teknologi juga berbicara mengenai kesesuaian (compatibility) antara teknologi yang akan diadopsi dengan budaya serta kebutuhan organisasi (Morteza et al., 2011 dalam Rahayu dan Day, 2015). Faktor organisasi, berbicara mengenai kesiapan internal dalam hal infrastruktur maupun kemampuan teknis yang berkaitan dalam pengadopsian teknologi (Zhu et al., 2006 dalam Rahayu dan Day, 2015). Selanjutnya, faktor lingkungan di dalam kerangka teori TOE membahas tentang pengaruh mitra bisnis (pemasok dan konsumen), kompetitor dan faktor pendukung eksternal dalam pengadopsian teknologi. Pada dasarnya faktor lingkungan ini bersifat given dan memiliki pengaruh berbeda dalam pengadopsian e-commerce.

\section{Faktor Pendukung Eksternal}

Implementasi e-commerce untuk UKM di Indonesia masih menghadapi kendala, baik dari aspek teknis maupun non-teknis. Oleh sebab itu, diperlukan sinergi antara pemerintah, perusahaan pengembang, pelaku usaha bahkan konsumen untuk mendukung aktivitas e-commerce (Suryana et al., 2013). 
Investasi $e$-commerce pada negara berkembang relatif lebih tinggi dibanding dengan rata-rata global, namun dalam hal ini pemerintah dan pelaku usaha diharapkan untuk tidak resisten dengan trend perkembangan yang ada (Molla et al., 2007). Indonesia sebagai salah satu negara berkembang dengan jumlah penduduk yang relatif besar menjadi surga untuk bisnis perdagangan. Penyediaan infrastruktur yang mampu menunjang transaksi perdagangan digital memberi ruang e-commerce untuk terus berkembang. Manfaat ekonomis dari perkembangan e-commerce tersebut dapat diperoleh melalui kolaborasi ide kreatif pelaku usaha dan adanya dukungan kebijakan pemerintah. Zhu dan Kraemer (2005) dalam Rahayu dan Day (2015) menilai faktor dukungan eksternal dalam konteks pengadopsian e-commerce melalui beberapa indikator. Pertama, melalui regulasi dan kebijakan pemerintah yang mampu melindungi pelaku usaha dalam transaksi bisnis digital. Kedua, melalui peran perusahaan pengembang sistem untuk ikut terlibat aktif dalam menyediakan fasilitas pelatihan dan konsultasi. Ketiga, insentif bagi pelaku usaha untuk menerapkan sistem teknologi digital dalam transaksi perdagangan. Sementara itu, Kurnia et al. (2015) dalam risetnya melibatkan aspek ketersediaan infrastruktur dalam faktor pendukung eksternal selain ketiga indikator tersebut.

\section{Faktor Penguasaan Teknologi Informasi}

Salah satu keunikan UKM jika dibandingkan dengan unit usaha berskala besar terletak pada gaya manajemennya. Pada umumnya UKM sangat bergantung pada intuisi para pemiliknya, sehingga proses pengambilan keputusan dilakukan terpusat (MacGregor dan Kartiwi, 2010). Kondisi tersebut membuat konteks individual menjadi salah satu pertimbangan khusus di dalam pengadopsian e-commerce (Rahayu dan Day, 2015). Banyak pihak yang menyadari pentingnya peran kompetensi individu berkaitan dengan penerimaan inovasi. Kesuksesan pengadopsian e-commerce untuk UKM sangat bergantung pada tingkat penguasaan teknologi informasi dari pemiliknya, sebagai inisiator dan penentu keputusan bisnis (Cloete et al., 2002 dalam Rahayu dan Day, 2015). Pada dasarnya kompetensi individu merupakan intangible assets yang dapat menjadi sumber keunggulan bagi UKM. Caldeira dan Ward (2001) menggunakan pendekatan teori resource based view untuk menjelaskan kesuksesan pengadopsian teknologi informasi pada UKM. Pada penelitian itu disimpulkan bahwa komitmen dari pemilik usaha sangat berpengaruh pada kesuksesan proses pengadopsian. Pemilik usaha dalam hal ini dinilai memiliki otoritas dan pengaruh yang signifikan terhadap individu lainnya untuk menerima perubahan (Markus, 1983; Thong et al., 1996 dalam Caldeira dan Ward, 2001). Keterlibatan pemilik usaha selama proses pengadopsian akan berdampak positif, baik dari sisi teknis maupun manajerial.

\section{PENGEMBANGAN MODEL}

\section{Penguasaan Teknologi Informasi dan Pengadopsian E-Commerce}

Olsen dan Eikebrokk (2009) melakukan penelitian eksploratori mengenai hubungan pelatihan, kompetensi dan performa bisnis digital. Penelitian ini dilakukan karena keterbatasan pembuktian empiris untuk topik terkait yang dilakukan pada ranah UKM. Melalui analisis model persamaan struktural (SEM-PLS) diketahui bahwa kompetensi pelaku usaha memiliki pengaruh positif signifikan terhadap performa bisnis digital. Salah satu dimensi dari performa bisnis tersebut adalah aspek komplementer, yaitu potensi manfaat dari kombinasi produk, layanan dan penerapan teknologi baru. Aspek komplementer merupakan dimensi performa bisnis digital pada UKM yang menerima pengaruh terkuat dari keberadaan kompetensi. Pada UKM, kompetensi pemilik usaha sangat menentukan kesuksesan pengadopsian teknologi (Ramdani et al., 2009; Lip-Sam dan Hock-Eam, 2011). Rutinitas penggunaan komputer dan tingkat pendidikan dari pemilik usaha terbukti memiliki pengaruh terhadap pengadopsian e-commerce (Lip-Sam dan Hock-Eam, 2011). Salah satu penelitian mengenai pengadopsian e-commerce pada UKM di Indonesia dilakukan oleh Rahayu dan Day (2015). Penelitian tersebut melibatkan 292 UKM yang disurvei dengan kuesioner online. Hasil dari analisis regresi berganda 
memperlihatkan penguasaan teknologi informasi menjadi determinan pengadopsian e-commerce yang paling dominan.

\section{Peran Faktor Pendukung Eksternal}

Faktor pendukung eksternal merupakan bagian dari konteks lingkungan, di mana telah diketahui sebelumnya bahwa hal ini bersifat given. Penelitian yang melibatkan faktor pendukung eksternal dalam pengadopsian e-commerce UKM menghasilkan hasil yang inkonsisten. Ahmad et al. (2014) melakukan penelitian dengan melibatkan 307 UKM di Malaysia dan memperoleh cukup bukti bahwa keberadaan perusahaan pengembang dan kebijakan pemerintah memiliki pengaruh yang positif signifikan terhadap pengadopsian e-commerce. Mereka menyatakan bahwa keterlibatan pemerintah yang dalam hal ini berupa pemberian insentif dan pendampingan selama proses set-up sistem sangat bermanfaat pada pengadopsian. Selanjutnya, Fahruzzaman dan Subriadi (2015) melakukan penelitian untuk menentukan faktor apa saja yang menentukan kesuksesan pengadopsian e-commercepadaUKMdiIndonesia. Penelitian tersebut dilakukan atas dasar kontribusi UKM yang relatif kecil dalam perekonomian jika dibandingkan dengan perusahaan besar. Salah satu penyebab minimnya kontribusi UKM adalah tingkat penggunaan teknologi informasi yang rendah. Penentuan faktor dilakukan melalui diskusi dengan ahli (expert) dan wawancara kepada beberapa stakeholders terpilih. Hasil penelitian menunjukkan kebijakan pemerintah dan dukungan perusahaan pengembang sistem dalam hal ini sangat menentukan kesuksesan pengadopsian e-commerce di Indonesia. Kontradiktif dengan hasil penelitian sebelumnya, Rahayu dan Day (2015) mendapati faktor pendukung eksternal tidak memiliki pengaruh signifikan terhadap pengadopsian e-commerce. Penelitian tersebut melibatkan 292 UKM di Indonesia dan belum memberi penjelasan lebih lanjut mengenai atas inkonsistensi hasil yang diperoleh. Sehingga dalam studi ini akan mencoba untuk melihat kemungkinan pengaruh moderasi dari faktor pendukung eksternal terhadap hubungan penguasaan teknologi informasi dan pengadopsian e-commerce. Spesifikasi model yang melibatkan pengaruh moderasi ini didasarkan pada inkonsistensi hubungan langsung terhadap pengadopsian e-commerce. Selain itu, faktor pendukung eksternal bersifat uncontrolable jika ditinjau melalui sudut pandang UKM sebagai unit analisis. Artinya, kebijakan pemerintah dan keterlibatan perusahaan pengembang dalam hal ini tidak dapat dikelola secara langsung oleh UKM.

\section{Kerangka Pemikiran Teoritis}

Berdasarkan pemaparan pengembangan model dengan dasar justifikasi penelitian terdahulu, maka dalam studi ini dirumuskan dua buah hipotesis penelitian. Hipotesis pertama $\left(\mathrm{H}_{1}\right)$, “penguasaan teknologi informasi berpengaruh positif dan signifikan terhadap pengadopsian e-commerce". Hipotesis kedua $\left(\mathrm{H}_{2}\right)$,"faktorpendukung eksternalberpengaruh positif dan signifikan terhadap hubungan antara penguasaan teknologi informasi dan pengadopsian e-commerce". Usulan kerangka pemikiran teoritis dalam studi ini diwujudkan seperti pada Gambar 1 berikut ini.

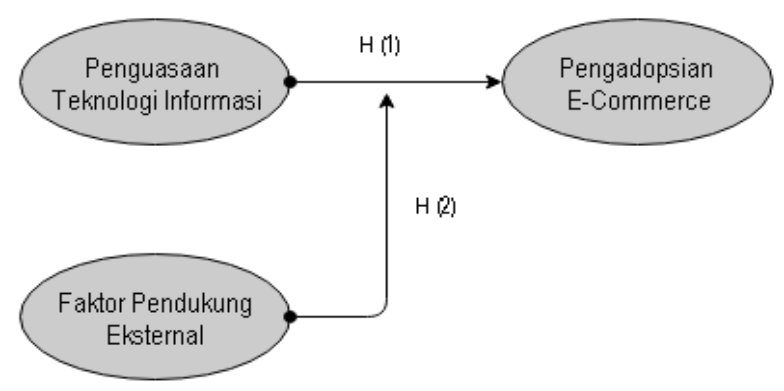

Gambar 1: Usulan model pengadopsian e-commerce pada UKM

Sumber: Hasil pengembangan kerangka pemikiran, 2017

\section{DAFTAR PUSTAKA}

Ahmad, S. Z., Abu Bakar, A. R., Faziharudean, T. M. \& Zaki, K. A. 2014. An empirical study of factors affecting e-commerce adoption among small and medium sized enterprises in a developing country: Evidence from Malaysia. Information Technology for Development, Vol. 21 No. 4

Caldeira, M. M. \& Ward, J. M. 2001. Using resouce-based theory to interpret the successful 
adoption and use of information systems \& technology in manufacturing small and medium sized enterprises. 9th European Conference on Information Systems

Cloete, E., Courtney, S. \& Fintz, J. 2002. Small businesses acceptance and adoption of e-commerce in the Western-Cape province of South Africa. Electronic Journal on Information Systems in Developing Countries, Vol. 10 No. 4

Fahruzzaman, F. \& Subriadi, A. P. 2015. An analysis of e-commerce adoption for small and medium enterprises in Indonesia. 1st International Seminar on Science and Technology

Kurnia, S., Choudrie, J., Mahbubur, M. M. \& Alzagooul, B. 2015. E-commerce technology adoption: A Malaysian grocery SME retail sector study. Journal of Business Research, Vol. 68 No. 9

Lip-Sam, T. \& Hock-Eam, L. 2011. Estimating the determinants of B2B e-commerce adoption among small and medium enterprises. International of Business and Society, Vol. 12 No. 1

MacGregor, M. C. \& Kartiwi, M. 2010. Perception of barriers to e-commerce adoption in SMEs in a developed and developing country: A comparison between Australia and Indonesia. Journal of Electronic Commerce in Organizations, Vol. 8 No. 1

Molla, A., Heeks, R. \& Balcells, I. 2006. Adding clicks to bricks: A case study of e-commerce adoption by a catalan small retailer. European Journal of Information Systems, Vol. 15 No. 4

Molla, A. \& Heeks, R. 2007. Exploring e-commerce benefits for businesses in a developing country. The nformation Society: An International Journal, Vol. 23 No. 2

Olsen, D. H. \& Eikebrokk, T. R. 2009. Training, competence and business performance: Evidence from e-business in european small and medium sized enterprises. International Journal of E-Business Research, Vol. 5 No. 1

Rahayu, R. \& Day, J. 2015. Determinant factors of e-commerce adoption by SMEs in developing country: Evidence from Indonesia. Procedia Social and Behavioral Sciences, Vol. 195

Ramdani, B., Kawalek, P. \& Lorenzo, O. 2009. Predicting SMEs adoption of enterprise systems. Journal of Enterprises Information Management, Vol. 22 No. 1

Sin, K. Y., Osman, A., Salahuddin, S. N., Abdullah, S., Lim, Y. J. \& Sim, C. L. 2016. Relative advantage and competitive pressure towards implementation of e-commerce: Overview of small and medium enterprises (SMEs). Procedia Economics and Finance, Vol. 35

Suryana, Y., Bayu, K. \& Jatnika, D. 2013. Promotion and product marketing models of small and medium enterprises (SMEs) through e-commerce. Advances in Management and Applied Economics, Vol. 3 No. 4

2016. Kemendag perkuat ekosistem e-commerce dan ekonomi kreatif untuk meningkatkan daya saing produk Indonesia. [www.kemendag.go.id]

. 2014. Pengguna internet Indonesia nomor enam dunia. [kominfo.go.id] . 2016. Jika ingin berkembang, UMKM harus manfaatkan kanal digital. [kompas.com] . 2017. Huawei: investasi UKM untuk digital bukan cuma infrastruktur. [metrotvnews. com] 